\title{
Calreticulin Is a Negative Regulator of Bronchial Smooth Muscle Cell Proliferation
}

\author{
Nicola Miglino, Michael Roth, Didier Lardinois, Michael Tamm, and Peter Borger \\ Departments of Biomedicine, Pulmonary Cell Research, and Thorax Surgery, University Hospital Basel, Hebelstrasse 20, \\ 4031 Basel, Switzerland \\ Correspondence should be addressed to Nicola Miglino, nicola.miglino@unibas.ch
}

Received 26 July 2011; Revised 1 November 2011; Accepted 23 November 2011

Academic Editor: Irene Heijink

Copyright ( 2012 Nicola Miglino et al. This is an open access article distributed under the Creative Commons Attribution License, which permits unrestricted use, distribution, and reproduction in any medium, provided the original work is properly cited.

Background. Calreticulin controls the $\mathrm{C} / \mathrm{EBP} \alpha \mathrm{p} 42 / \mathrm{p} 30$ at the translational level trough a cis-regulatory CNG rich loop in the CEBPA mRNA. We determined the effects of steroids and long-acting beta-agonists on the p42/p30 ratio and on calreticulin expression in primary human bronchial smooth muscle (BSM) cells. Methods. The effects of budesonide $\left(10^{-8} \mathrm{M}\right)$ and formoterol $\left(10^{-8} \mathrm{M}\right)$ were studied in BSM cells pre-treated with siRNA targeting calreticulin. The expression of C/EBP $\alpha$ and calreticulin was determined by immuno-blotting. Automated cell counts were performed to measure proliferation. Results. All tested BSM cell lines $(n=5)$ expressed C/EBP $\alpha$ and calreticulin. In the presence of 5\% FBS, the p42/p30 ratio significantly decreased $(n=3, P<0.05)$ and coincided with BSM cell proliferation. High levels of calreticulin were associated with a decreased p42/p30 isoform ratio. FBS induced the expression of calreticulin $(n=3, P<0.05)$, which was further increased by formoterol. siRNA targeting calreticulin increased the p42/p30 ratio in non-stimulated BSM cells and significantly inhibited the proliferation of PDGF-BB-stimulated BSM cells $(n=5, P<0.05)$. Neither budesonide nor formoterol restored the $\mathrm{p} 42$ isoform expression. Conclusions. Our data show calreticulin is a negative regulator of $\mathrm{C} / \mathrm{EBP} \alpha$ protein expression in BSM cells. Modulation of calreticulin levels may provide a novel target to reduce BSM remodeling.

\section{Introduction}

An important feature of asthma pathology is airway wall remodeling, characterized by a thickened basement membrane and an increase with respect to the bulk of the bronchial smooth muscle (BSM) cells [1-3]. Earlier we showed that the increased proliferation rate of asthmatic BSM cells was normalized after the introduction of an expression vector for full length $\mathrm{C} / \mathrm{EBP} \alpha \mathrm{mRNA}$ [4]. We have further provided data showing a disease specific expression of C/EBPisoforms in asthma and COPD [5].

$\mathrm{C} / \mathrm{EBP} \alpha$ can be expressed as full length and truncated protein isoforms, commonly referred to as $\mathrm{p} 42$ and $\mathrm{p} 30$. The full length $\mathrm{C} / \mathrm{EBP} \alpha(\mathrm{p} 42)$ functions as a proliferation inhibitor, whereas the truncated $\mathrm{C} / \mathrm{EBP} \alpha(\mathrm{p} 30)$ does not have this effect $[6,7]$. A decreased $\mathrm{p} 42 / \mathrm{p} 30$ ratio may therefore render BSM cells a growth advantage and result in thicker layers of muscles around the airways as observed in the lungs of asthma patients.
The standard therapy for asthma consists of drugs that reduce airway inflammation (predominantly glucocorticoids) and induce relaxation of the smooth muscles (predominantly $\beta_{2}$-agonists). We have earlier shown the molecular biological basis of the interaction of both classes of drugs, which involved the formation of a complex consisting of the glucocorticoid receptor and $\mathrm{C} / \mathrm{EBP} \alpha[8-11]$. This complex is able to activate the cell cycle inhibitor p $21^{\text {cip } 1 / \text { wafl } 1}[9,10]$, thus demonstrating an interactive negative regulatory network for cell proliferation. The observed diminished expression of $\mathrm{C} / \mathrm{EBP} \alpha$ in BSM cells of asthma patients is mainly due to posttranscriptional regulation affecting the translation of the CEBPA mRNA [12, 13].

In general, two mechanisms can be involved in translation control: "global" and "selective". Global control acts on all mRNAs in a nonspecific manner, whereas selective translation regulation targets a specific subset of mRNAs. These specific mRNAs often have cis-regulatory sequences that sense subtle changes in the activity of the translation 


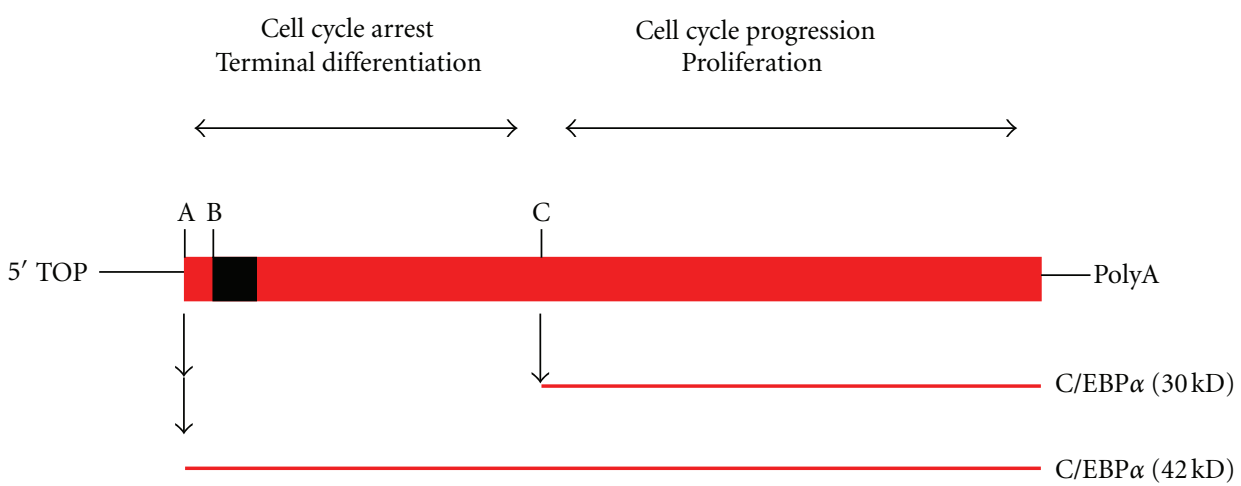

(a)

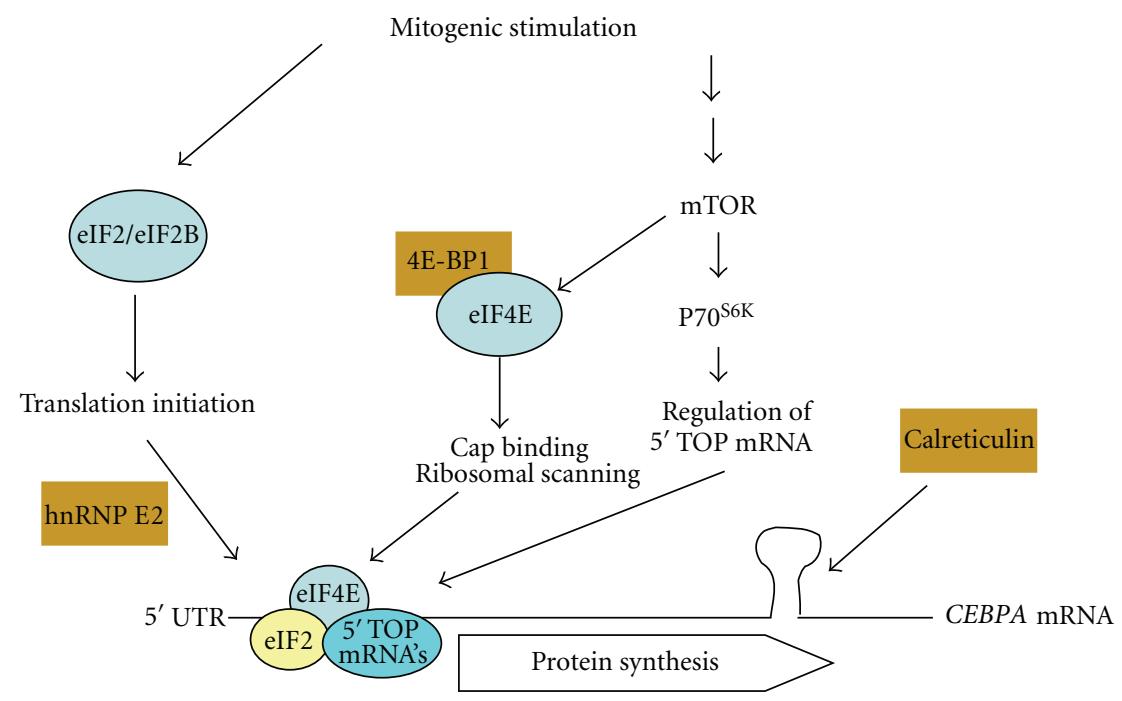

(b)

FIgURE 1: (a) Simplified scheme of the CEBPA mRNA. Due to alternative translation start sites (A, B, and C), full length (p42) and truncated (p30) $\mathrm{C} / \mathrm{EBP} \alpha$ proteins with distinct functions can be formed. Start site B is out of frame and determines whether A or B is accessible for translation, hence producing either $\mathrm{p} 42$ or $\mathrm{p} 30 \mathrm{C} / \mathrm{EBP} \alpha$ proteins. (b) Schematic representation showing three important signaling pathways for the translation control of CEBPA messenger RNA: (1) the pathway leading to activation of the eukaryotic initiation factors eIF2 and eIF2B, which is counteracted by hnRNPE2, (2) the pathway of mTOR and eukaryotic initiation factor 4E (eIF4E), which is inhibited by $4 \mathrm{E}-\mathrm{BP} 1$, and (3) the pathway leading to calreticulin (CRT) expression, a protein that binds to a double-stranded RNA loop and prevents the translation of full length C/EBP $\alpha$ proteins. Abbreviations: $5^{\prime}$ TOP: $5^{\prime}$ tract of pyrimidine; mTOR: mammalian target of rapamycin.

machinery or form loops that affect the accessibility of the appropriate translation start sites. It is now well documented that the CEBPA mRNA can be expressed as a full length protein $(\mathrm{p} 42)$ or a truncated form (p30) $[6,7,14-18]$. The p42/p30 ratio is predominantly controlled at the translational level [15-18]. Full lengths (p42) and truncated (p30) $\mathrm{C} / \mathrm{EBP} \alpha$ proteins are generated from one single $5^{\prime}$ tract of pyrimidine ( $5^{\prime}$ TOP) CEBPA mRNA (Figure 1(a)). Three important signaling pathways regulate the translation of $5^{\prime}$ TOP messengers (Figure 1(b)). The first is the ubiquitous eukaryotic initiation factor 2 (eIF2). The second is leading to activation of mammalian target of rapamycin (mTOR) and subsequent activation of eukaryotic initiation factor $4 \mathrm{E}$ (eIF4E). These pathways are stringently controlled by specific inhibitory proteins, including hnRNPE2, which interferes with translation initiation, and $4 \mathrm{E}-\mathrm{BP} 1$, a protein that prevents ribosomal scanning [19]. The third level of control of
CEBPA mRNA translation is found in a cis-regulatory double-stranded RNA loop, which provides a docking site for calreticulin. When calreticulin is bound to this sequence, translation of the full length $\mathrm{C} / \mathrm{EBP} \alpha(\mathrm{p} 42)$ is reduced [20].

Here, we isolated and maintained primary human BSM cells and studied the involvement of calreticulin in the regulation of CEBPA mRNA translation and whether budesonide and formoterol are able to modulate the $\mathrm{p} 42 / \mathrm{p} 30$ ratio.

\section{Material and Methods}

2.1. Tissue Specimens and Cell Cultures. Lung tissue specimens were obtained from the Department of Internal Medicine, Pneumology, and the Department of Thorax Surgery, University Hospital Basel, Switzerland, with the approval of the local Ethical Committee and written consent of all patients. BSM cells were established as previously described 
[10] and grown in RPMI 1640 (Lonza, Basel, Switzerland) supplemented with $5 \%$ fetal bovine serum (FBS), $8 \mathrm{mM}$ L-glutamine, $20 \mathrm{mM}$ HEPES, and 1\% MEM vitamin mix (Gibco, Paisley, UK). Neither antibiotics nor antimycotics were added at any time.

2.2. Cell Treatment and Drugs. Confluent BSM cells were cultured for 24 hours in the presence or absence of 5\% FBS and grown in the presence of an optimal concentration $[4,8-$ 10] of budesonide $\left(10^{-8} \mathrm{M}\right)$, formoterol $\left(10^{-8} \mathrm{M}\right)$, or a combination of both drugs for 24 and 96 hours.

2.3. Small Inhibitory RNA (siRNA) Treatment. Transfection with siRNA for calreticulin or negative control (Ambion, Austin, USA) was performed according manufacturer protocol. Cells (70\% confluence) were plated into 6 well plates and transiently transfected with siRNA $(50 \mathrm{nM})$ for 6 hours. Thereafter, fresh RPMI was added for 24 hours. Then, cells were cultured in presence or absence of budesonide $\left(10^{-8} \mathrm{M}\right)$ or formoterol $\left(10^{-8} \mathrm{M}\right)$. Cell lysates were collected after 24 hours and prepared for immuneblot analysis.

2.4. Protein Isolation and Analysis by Immunoblot. Cellular proteins were isolated from confluent cells by dissociation in lysis buffer (62,5 mM Tris- $\mathrm{HCl}$ (pH 6.8), 2\% SDS, $2 \% \beta$ mercaptoethanol, $10 \%$ glycerol) and denaturation in sample buffer (3x Laemmli buffer with $\beta$-mercapto-ethanol) and boiling for $5 \mathrm{~min}$. Equal protein amounts were loaded onto a 4-12\% PAGE-gel (Pierce Biotech, Thermo Fisher Scientific, Rockford, IL, USA) and were size fractionated by electrophoresis $(1 \mathrm{hr}, 100 \mathrm{~V}$, open A). The gel was sandwiched between two nitrocellulose membranes (Biorad, Reinach, Switzerland), and proteins were transferred (transfer buffer: $0.05 \mathrm{M} \mathrm{NaCl}, 2 \mathrm{mM}$ Na-EDTA, $0.1 \mathrm{mM}$ DTT, $10 \mathrm{mM}$, Tris $\mathrm{HCl}(\mathrm{pH} 7.5))$ overnight $\left(50^{\circ} \mathrm{C}\right)$. Protein transfer and equal loading were confirmed by Ponceau's staining. The membranes were blocked (10 min) in 3\% bovine serum albumin (Roche, Rotkreuz, Switzerland) in 1x phosphate buffered saline with $0.05 \%$ Tween-20 (PBST). The membranes were incubated ( 1 hour) at room temperature (RT) with one of the antibodies to C/EBP $\alpha$ (Santa Cruz Biotech, Santa Cruz, USA) and calreticulin (Santa Cruz Biotech). Membranes were then washed $(3 \times 5 \mathrm{~min})$ and incubated ( 1 hour, RT) with horseradish labeled species-specific antibodies (Santa Cruz Biotech). The membranes were washed $(3 \times 5 \mathrm{~min})$ with and incubated (5 min) with ECL-substrate (Pierce), and protein bands were visualized on X-ray films (Fuji Film, Medical Xray film, Luzern, Switzerland). Protein bands were semiquantified by an image analysis system (ImageJ). Protein expression was normalized to $\alpha$-tubulin as internal control. The presented $\mathrm{p} 42 / \mathrm{p} 30$ ratios were calculated from normalized densitometry data.

2.5. Proliferation. BSM cells were plated in a 24 wells plate at a density of $10^{4}$ cells/well. Next cells were grown for 24 hours in the presence of FBS (5\%), before being serum starved for 24 hours. Then, cells were incubated in absence or presence of FBS (5\%) for 96 hours. After trypsinization cells, were counted manually and/or by using an automated particle counter (Coulter).

2.6. Statistics. Cytokine and proliferation data are presented as mean \pm SEM, immunoblot analysis is shown as mean \pm SEM after densitometric image analysis (ImageJ software, National Institute of Mental Health, Bethesda, MD, USA) of independent experiments. Paired/unpaired Student's $t$-test was performed, and $P$ values $<0.05$ were considered significant.

\section{Results}

3.1. Effects of FBS, Budesonide, and Formoterol on $p 42 / 30$ Ratios. To determine the effect of FBS, budesonide, and formoterol on p42/p30, BSM cells $(n=3)$ were cultured for 0 , 24 , and 96 hours in growth medium (5\% FBS) supplemented with either budesonide $\left(10^{-8} \mathrm{M}\right)$ or formoterol $\left(10^{-8} \mathrm{M}\right)$. FBS (5\%) significantly reduced p42 C/EBP $\alpha$ levels $(n=3 ; P<0.05)$, both after 24 and 96 hours (Figure $2(\mathrm{a})$ ). Concomitantly, p30 C/EBP $\alpha$ levels were significantly increased $(n=3 ; P<0.05)$ at both time points, resulting in reduced p42/p30 ratios which are presented in Figure 2(b). The addition of formoterol to FBS stimulated BSM cells further reduced the $\mathrm{p} 42 / \mathrm{p} 30$ ratio below 0.01 , whereas budesonide did not modify the effect of FBS (Figure 2(b)). As shown in Figure 3(c), a reduced p42/p30 ratio coincided with a significantly increased proliferation rate of 5\% FBSstimulated BSM cells relative to nonstimulated cells $(n=4$; $P<0.05)$.

3.2. Calreticulin Levels Coincide with C/EBP p42/p30 Ratios. BSM cells were incubated with FBS (5\%) supplemented with budesonide $\left(10^{-8} \mathrm{M}\right)$ or formoterol $\left(10^{-8} \mathrm{M}\right)$. As demonstrated in Figure 3(a), resting BSM cells expressed low levels of calreticulin, which were significantly upregulated after 24 an 96 hours in the presence of 5\% FBS, only. After 96 hours, budesonide $\left(10^{-8} \mathrm{M}\right)$ slightly restored the expression of the $\mathrm{p} 42$ isoform, but the p42/p30 ratio was unaffected. The expression of calreticulin protein coincided with low levels of $\mathrm{C} / \mathrm{EBP} \alpha(\mathrm{p} 42)$ and high levels of C/EBP $\alpha(\mathrm{p} 30)$ : the $\mathrm{p} 42 / \mathrm{p} 30$ ratio significantly decreased $(n=3 ; P<0.05)$. As shown in Figure 3(b), calreticulin-specific siRNA significantly decreased the expression of calreticulin protein $(n=3, P<$ $0.05)$. The knockdown of calreticulin only increased the expression of $\mathrm{C} / \mathrm{EBP} \alpha(\mathrm{p} 42)$ in untreated BSM cells. Finally, BSM cells were transfected with increasing concentrations of calreticulin-specific siRNA and incubated in presence and absence of PDGF-BB for 96 hours. As demonstrated in Figure 3(c), siRNA for calreticulin dose-dependently inhibited the proliferation of PDGF-BB-stimulated BSM cells $(n=5 ; P<$ 0.05 for calreticulin-siRNA ranging from 0.1 to $5.0 \mathrm{ng} / \mathrm{mL}$ ), whereas the control siRNA did not have an effect on PDGFBB-induced proliferation $(n=5 ; P=0.59)$.

\section{Discussion}

An increased capacity to proliferate is a key feature of BSM cells obtained from asthma patients and may provide an 


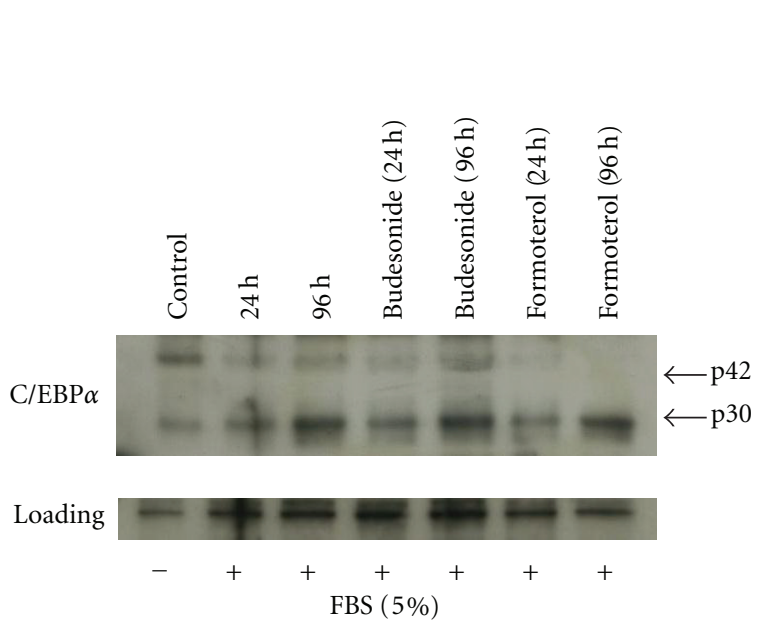

(a)

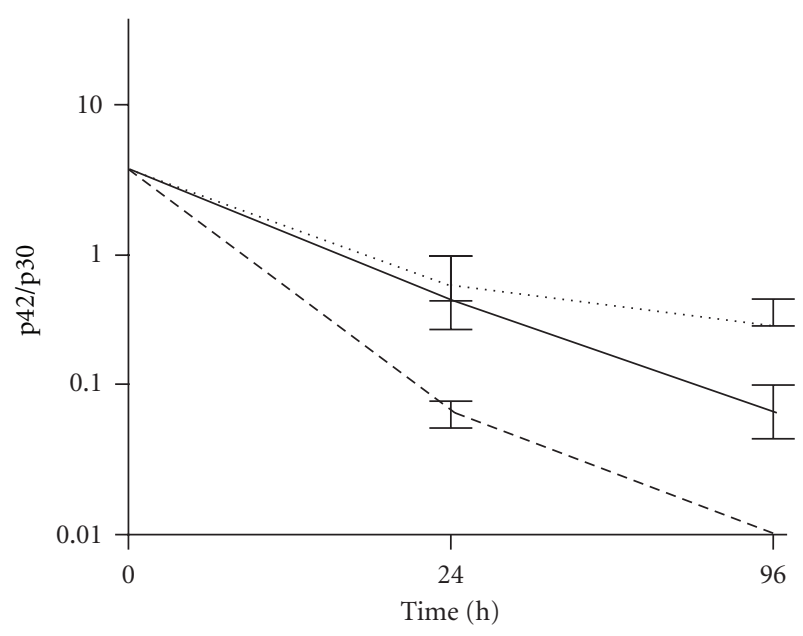

(b)

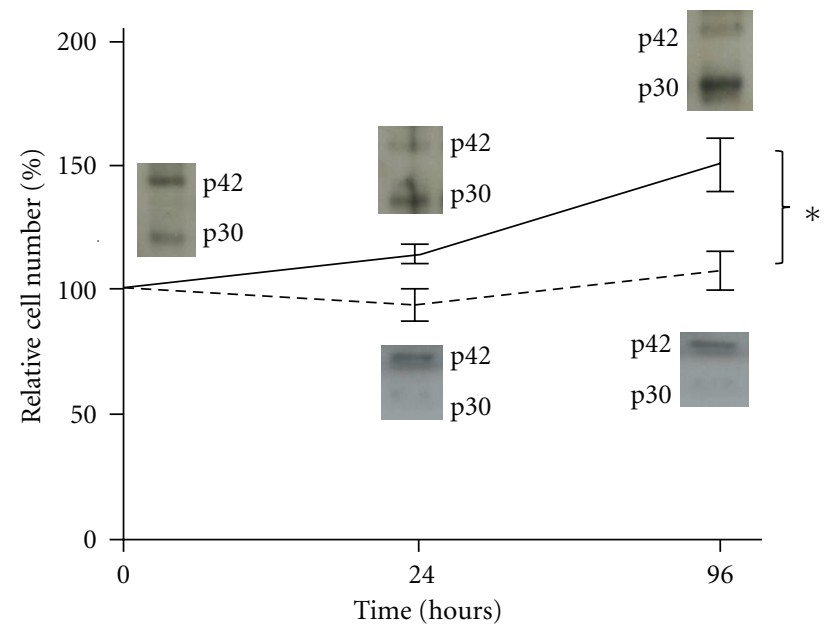

(c)

FIGURE 2: (a) Representative immunoblot analysis demonstrating the modulatory effect of asthma drugs on the C/EBP $\alpha$ (p42) and C/EBP $\alpha$ (p30) expression pattern in human BSM cells. BSM cells were untreated (control) or incubated with 5\% FBS alone, and in the presence of budesonide $\left(10^{-8} \mathrm{M}\right)$ or formoterol $\left(10^{-8} \mathrm{M}\right)$ for 24 and 96 hours. Similar data were obtained in two additional cell lines. (b) C/EBP $\alpha$ p42/p30 ratios (mean \pm SEM; $n=3$ ) in BSM cells cultured for 0, 24, and 96 hours with 5\% FBS (solid line), budesonide (dotted line), or formoterol (dashed line). (c) C/EBP $\alpha$ (p42 and p30) expression patterns projected in the proliferation curve of BSM cells. Cells were incubated for 0, 24, and 96 hours in absence (dashed line) or presence of 5\% FBS (solid line). Data are expressed as a percentage of the cell number at $t=0$ (control). * Significant difference between untreated and FBS-stimulated cells $(P<0.05 ; n=4)$. Photo insets show the corresponding ratio of $\mathrm{C} / \mathrm{EBP} \alpha \mathrm{p} 42$ and $\mathrm{p} 30$ expression of one representative experiment at $t=0 \mathrm{~h}$ (control), $t=24 \mathrm{~h}$, and $t=96 \mathrm{~h}$.

explanation for the observed increase of BSM bundles surrounding the bronchi of asthma patients [21]. We have extensively explored the role of the $C E B P$ transcription factor-family in BSM cell proliferation and concluded that the expression and regulation of $\mathrm{C} / \mathrm{EBP} \alpha$ isoforms may be crucial to understand the proliferation control of BSM cells $[4,5,12$, 13]. In our present study, we demonstrated that normal BSM cells express $\mathrm{C} / \mathrm{EBP} \alpha(\mathrm{p} 42)$ and $\mathrm{C} / \mathrm{EBP} \alpha$ (p30) isoforms, as well as their specific translation regulator calreticulin. Moreover, we observed a specific relation between these proteins, that is, when calreticulin levels are high, the $\mathrm{p} 42 / \mathrm{p} 30$ ratio is small. Furthermore, we showed that in the presence of serum, the p42/p30 ratio significantly decreased. Addition of budesonide, but not formoterol, slightly restored the $\mathrm{p} 42$ levels. Restoring p42 levels would theoretically restore the responsiveness of BSM cells to budesonide and/or formoterol, since only full length $\mathrm{C} / \mathrm{EBP} \alpha$ proteins formed a complex with the glucocorticoid receptor to induce the cell cycle inhibitor $\mathrm{p} 21^{\text {cipl/waf1 }}[9,11]$. Both budesonide and formoterol were unable to significantly increase the p42/p30 ratio, however. The incapability of budesonide and formoterol to induce the expression of $\mathrm{C} / \mathrm{EBP} \alpha$ (p42) may explain why the airway remodeling observed in asthma patients is resistant to therapy involving steroids and/or $\beta$-mimetics [22].

We have earlier reported that an impaired translationinitiation of the CEBPA mRNA in BSM cells of asthma patients was associated with the decreased expression of the translation regulator eIF4E [12]. We were unable to detect significant differences with respect to eIF4E levels between 


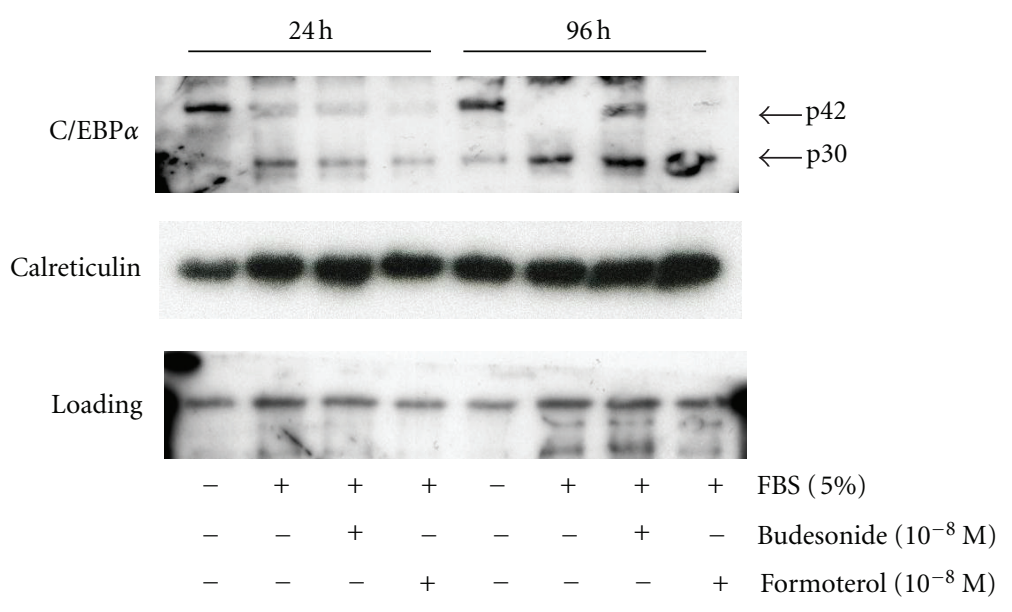

(a)
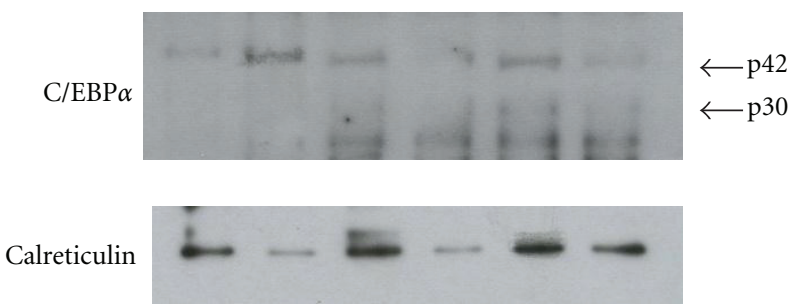

Loading
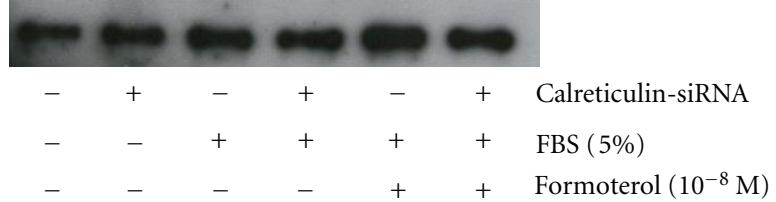

(b)

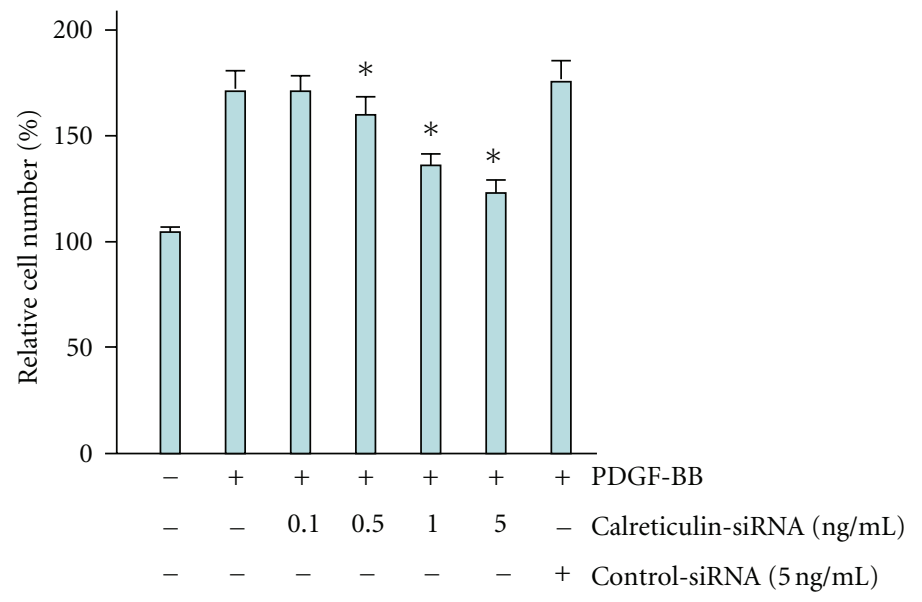

(c)

FIGURE 3: (a) Immunoanalyses demonstrating the effect of asthma drugs on the C/EBP $\alpha$ (p42), C/EBP $\alpha$ (p30), and calreticulin expression pattern. BSM cells were untreated or incubated with $5 \%$ FBS alone, and in the presence of budesonide $\left(10^{-8} \mathrm{M}\right)$ or formoterol $\left(10^{-8} \mathrm{M}\right)$ for 24 and 96 hours. (b) Immunoanalyses demonstrating C/EBP $\alpha$ (p42), C/EBP $\alpha$ (p30), and calreticulin expression patterns in BSM cells after transient knockout of the calreticulin by siRNA. BSM cells were untreated or incubated with 5\% FBS alone, and in the presence of formoterol $\left(10^{-8} \mathrm{M}\right)$ for 24 hours. (c) BSM cell proliferation (presented as relative cell counts) in response to PDGF-BB (5 ng/mL) and the effect of increasing concentrations calreticulin-specific siRNA relative to control siRNA (as indicated). * Significant inhibition relative to PDGF-BBstimulated cells $(P<0.05 ; n=5)$. 
house-dust-mite-challenged BSM cells isolated from asthmatic and nonasthmatic subjects, however [13]. Therefore, we proposed that calreticulin, a protein initially identified as an endoplasmic reticulum luminal chaperone that controls the regulation of intracellular $\mathrm{Ca}^{2+}$ homeostasis [23], could be pivotal in the downregulation of $\mathrm{C} / \mathrm{EBP} \alpha$ translation and may be one of the key regulators to explain low levels of $\mathrm{C} / \mathrm{EBP} \alpha$ proteins in BSM cells of asthma patients. Binding of calreticulin has been shown to inhibit the translation of the CEBPA mRNA, as a result of a direct interaction of calreticulin and the CEBPA transcript. As depicted in Figure 1(b), calreticulin binds to a stem loop within the CEBPA mRNA, which is formed by internal base-pairing of the GCN repeat motif [24]. When calreticulin is bound to this loop, translation of the full length $\mathrm{C} / \mathrm{EBP} \alpha(\mathrm{p} 42)$ can no longer be generated and $\mathrm{p} 21^{\mathrm{cip} 1 / \mathrm{wafl}}$ cannot be formed. An inverse relationship of $\mathrm{C} / \mathrm{EBP} \alpha$ and calreticulin had been demonstrated in adipocytes, where calreticulin inhibited adipogenesis by suppressing the expression of $\mathrm{C} / \mathrm{EBP} \alpha$ [25]; an observation that was also reported in acute myeloid leukemia [26]. Here, we demonstrated that the same mechanism operates in normal BSM cells, because a transient suppression of calreticulin by siRNA increased $\mathrm{C} / \mathrm{EBP} \alpha(\mathrm{p} 42)$ levels in resting BSM cells. It should be noted, however, that in proliferating cells additional mechanisms operate to control $\mathrm{C} / \mathrm{EBP} \alpha$ isoforms $[4,12,13]$. Therefore, the decrease of the $\mathrm{C} / \mathrm{EBP} \alpha$ protein level in BSM cells of asthma patients may only partially be related to increased calreticulin.

Our current data show that in the presence of $5 \%$ FBS BSM cells rapidly decreased the p42/p30 ratio. Formoterol was able to even further reduce the $\mathrm{p} 42 / \mathrm{p} 30$ values. Here, the p42/p30 value went below 0.01 , demonstrating an additive effect relative to FBS alone (Figure 2(b)). This additive effect was not observed with budesonide and indicates that formoterol also activates additional pathways not induced by budesonide and independent of $\mathrm{C} / \mathrm{EBP} \alpha(\mathrm{p} 42)$. It should be emphasized that both $\mathrm{C} / \mathrm{EBP} \alpha(\mathrm{p} 42)$ and $\mathrm{C} / \mathrm{EBP} \alpha(\mathrm{p} 30)$ can bind to the same DNA motifs but that p30 cannot exert the antiproliferative effects of $\mathrm{p} 42$. The $\mathrm{p} 42$, however, is a direct inhibitor of cell cycle progression.

Finally, we found that the siRNA targeting calreticulin dose-dependently inhibited BSM cells proliferation and restored $\mathrm{C} / \mathrm{EBP} \alpha(\mathrm{p} 42)$ in nonstimulated BSM cells only. This shows that, although FBS was able to induce calreticulin, it does not exert its effects through an increased expression of calreticulin. Rather, FBS and PDGF may affect the transcription of the gene directly or redirect the translation machinery to alternative start codons present in the CEBPA mRNA as described previously [14-16]. Calreticulin levels were slightly increased after 96 hours of treatment with formoterol. The significance of this observation is currently unclear, but may indicate an additional inhibitory effect on proproliferative members of the CEBP gene family [24].

Taken together, our current data demonstrate that the translation-controlled $\mathrm{C} / \mathrm{EBP} \alpha(\mathrm{p} 42)$ and its counterpart (p30) are present in BSM cells. Calreticulin functions as an important control protein for BSM cell proliferation, but largely independent of the transactivating $\mathrm{C} / \mathrm{EBP} \alpha$ protein isoform. However, modulation of calreticulin levels-either (epi) genetically or by administration of specific drugs-may be a novel tool to target remodeling parameters involving BSM cells, both in vitro and in vivo.

\section{Acknowledgments}

This study was supported by the Swiss National Science Foundation (grants no. 310030-133109 and 310030-130740) and by a research grant of the Gottfried and Julia BangerterRyhner-Stiftung (8472/HEG-DSV).

\section{References}

[1] M. Hoshino, Y. Nakamura, and J. J. Sim, "Expression of growth factors and remodelling of the airway wall in bronchial asthma," Thorax, vol. 53, no. 1, pp. 21-27, 1998.

[2] D. S. Postma and W. Timens, "Remodeling in asthma and chronic obstructive pulmonary disease," Proceedings of the American Thoracic Society, vol. 3, no. 5, pp. 434-439, 2006.

[3] P. O. Girodet, A. Ozier, I. Bara, J. M. Tunon de Lara, R. Marthan, and P. Berger, "Airway remodeling in asthma: new mechanisms and potential for pharmacological intervention," Pharmacology and Therapeutics, vol. 130, no. 3, pp. 325-337, 2011.

[4] M. Roth, P. R. Johnson, P. Borger et al., "Dysfunctional interaction of $\mathrm{C} / \mathrm{EBP} \alpha$ and the glucocorticoid receptor in asthmatic bronchial smooth-muscle cells," The New England Journal of Medicine, vol. 351, no. 6, pp. 560-574, 2004.

[5] P. Borger, H. Matsumoto, S. Boustany et al., "Disease-specific expression and regulation of CCAAT/enhancer-binding proteins in asthma and chronic obstructive pulmonary disease," Journal of Allergy and Clinical Immunology, vol. 119, no. 1, pp. 98-105, 2007.

[6] F. T. Lin, O. A. MacDougald, A. M. Diehl, and M. D. Lane, "A $30-\mathrm{kDa}$ alternative translation product of the CCAAT/enhancer binding protein $\alpha$ message: transcriptional activator lacking antimitotic activity," Proceedings of the National Academy of Sciences of the United States of America, vol. 90, no. 20, pp. 9606-9610, 1993.

[7] C. Nerlov, "The C/EBP family of transcription factors: a paradigm for interaction between gene expression and proliferation control," Trends in Cell Biology, vol. 17, no. 7, pp. 318-324, 2007.

[8] O. Eickelberg, M. Roth, R. Lörx et al., "Ligand-independent activation of the glucocorticoid receptor by $\beta 2$ - adrenergic receptor agonists in primary human lung fibroblasts and vascular smooth muscle cells," Journal of Biological Chemistry, vol. 274, no. 2, pp. 1005-1010, 1999.

[9] J. J. Rüdiger, M. Roth, M. P. Bihl et al., "Interaction of C/EBP $\alpha$ and the glucocorticoid receptor in vivo and in nontransformed human cells," The FASEB Journal, vol. 16, no. 2, pp. 177-184, 2002.

[10] M. Roth, P. R. Johnson, J. J. Rüdiger et al., "Interaction between glucocorticoids and $\beta 2$ agonists on bronchial airway smooth muscle cells through synchronised cellular signalling," The Lancet, vol. 360, no. 9342, pp. 1293-1299, 2002.

[11] J. Q. Yang, J. J. Rüdiger, S. Goulet et al., "Cell density and serum exposure modify the function of the glucocorticoid receptor C/EBP complex," American Journal of Respiratory Cell and Molecular Biology, vol. 38, no. 4, pp. 414-422, 2008.

[12] P. Borger, N. Miglino, M. Baraket, J. L. Black, M. Tamm, and M. Roth, "Impaired translation of CCAAT/enhancer binding 
protein $\alpha$ mRNA in bronchial smooth muscle cells of asthmatic patients," Journal of Allergy and Clinical Immunology, vol. 123, no. 3, pp. 639-645, 2009.

[13] N. Miglino, M. Roth, M. Tamm, and P. Borger, "House dust mite extract downregulates $\mathrm{C} / \mathrm{EBP} \alpha$ in asthmatic bronchial smooth muscle cells," European Respiratory Journal, vol. 38, no. 1, pp. 50-58, 2011.

[14] A. L. Welm, N. A. Timchenko, and G. J. Darlington, " $\mathrm{C} / \mathrm{EBP} \alpha$ regulates generation of $\mathrm{C} / \mathrm{EBP} \beta$ isoforms through activation of specific proteolytic cleavage," Molecular and Cellular Biology, vol. 19, no. 3, pp. 1695-1704, 1999.

[15] C. F. Calkhoven, P. R. Bouwman, L. Snippe, and G. AB, "Translation start site multiplicity of the CCAAT/enhancer binding protein $\alpha$ mRNA is dictated by a small $5^{\prime}$ open reading frame," Nucleic Acids Research, vol. 22, no. 25, pp. 5540-5547, 1994.

[16] C. F. Calkhoven, C. Muller, and A. Leutz, "Translational control of $\mathrm{C} / \mathrm{EBP} \alpha$ and $\mathrm{C} / \mathrm{EBP} \beta$ isoform expression," Genes and Development, vol. 14, no. 15, pp. 1920-1932, 2000.

[17] V. Wiesenthal, A. Leutz, and C. F. Calkhoven, "A translation control reporter system (TCRS) for the analysis of translationally controlled processes in the vertebrate cell," Nucleic Acids Research, vol. 34, no. 3, article e23, 2006.

[18] V. Wiesenthal, A. Leutz, and C. F. Calkhoven, "Analysis of translation initiation using a translation control reporter system," Nature Protocols, vol. 1, no. 3, pp. 1531-1537, 2006.

[19] C. F. Calkhoven, C. Müller, and A. Leutz, "Translational control of gene expression and disease," Trends in Molecular Medicine, vol. 8, no. 12, pp. 577-583, 2002.

[20] D. Helbling, B. U. Mueller, N. A. Timchenko et al., "The leukemic fusion gene AML1-MDS1-EVI1 suppresses CEBPA in acute myeloid leukemia by activation of Calreticulin," Proceedings of the National Academy of Sciences of the United States of America, vol. 101, no. 36, pp. 13312-13317, 2004.

[21] P. R. Johnson, M. Roth, M. Tamm et al., "Airway smooth muscle cell proliferation is increased in asthma," American Journal of Respiratory and Critical Care Medicine, vol. 164, no. 3, pp. 474-477, 2001.

[22] P. O. Girodet, A. Ozier, I. Bara, J.-M. Tunon de Lara, R. Marthan, and P. Berger, "Airway remodeling in asthma: new mechanisms and potential for pharmacological intervention," Pharmacology and Therapeutics, vol. 130, no. 3, pp. 325-337, 2011.

[23] M. Michalak, J. Groenendyk, E. Szabo, L. I. Gold, and M. Opas, "Calreticulin, a multi-process calcium-buffering chaperone of the endoplasmic reticulum," Biochemical Journal, vol. 417, no. 3, pp. 651-666, 2009.

[24] L. T. Timchenko, P. Iakova, A. L. Welm, Z. J. Cai, and N. A. Timchenko, "Calreticulin interacts with $\mathrm{C} / \mathrm{EBP} \alpha$ and $\mathrm{C} /$ $\mathrm{EBP} \beta$ mRNAs and represses translation of C/EBP proteins," Molecular and Cellular Biology, vol. 22, no. 20, pp. 7242-7257, 2002.

[25] E. Szabo, Y. Qiu, S. Baksh, M. Michalak, and M. Opas, "Calreticulin inhibits commitment to adipocyte differentiation," Journal of Cell Biology, vol. 182, no. 1, pp. 103-116, 2008.

[26] D. Helbling, B. U. Mueller, N. A. Timchenko et al., "CBFBSMMHC is correlated with increased calreticulin expression and suppresses the granulocytic differentiation factor CEBPA in AML with inv(16)," Blood, vol. 106, no. 4, pp. 1369-1375, 2005. 


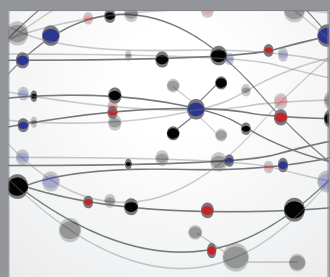

The Scientific World Journal
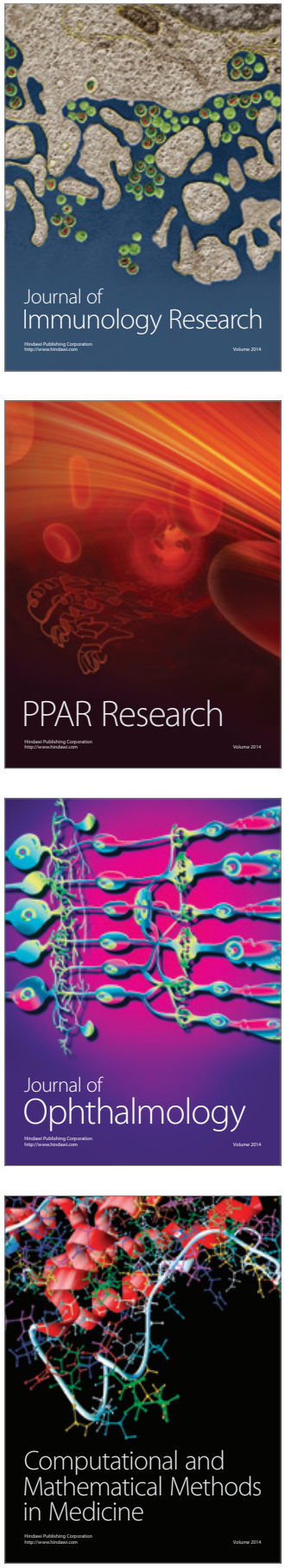

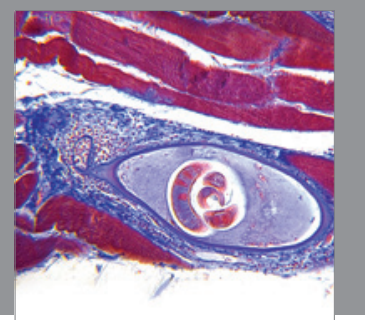

Gastroenterology

Research and Practice
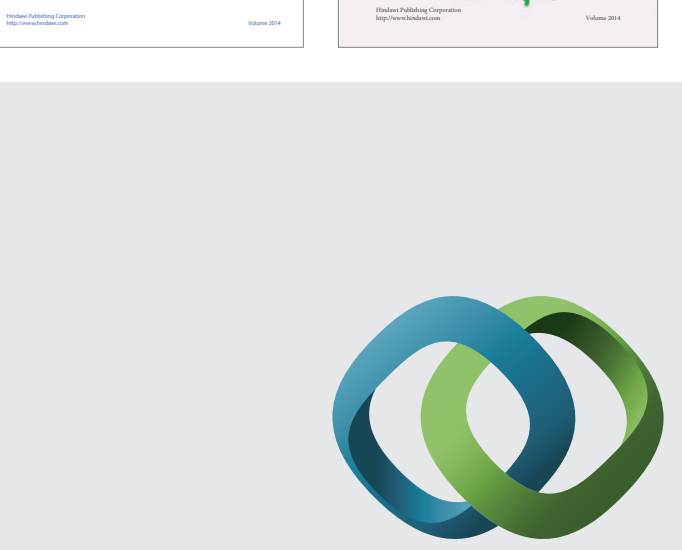

\section{Hindawi}

Submit your manuscripts at

http://www.hindawi.com
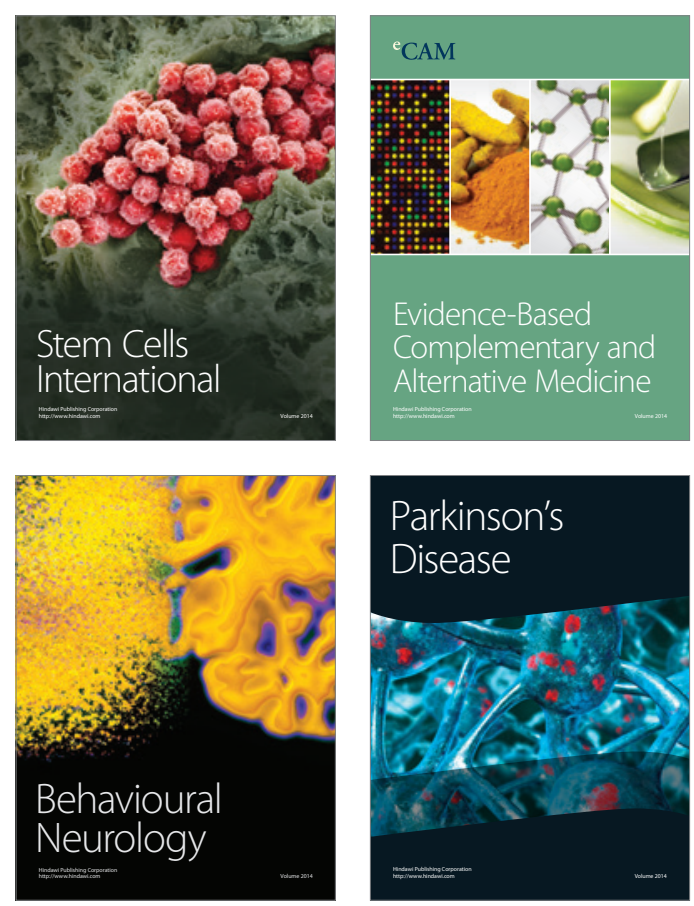

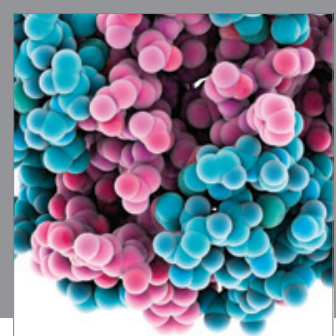

Journal of
Diabetes Research

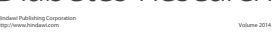

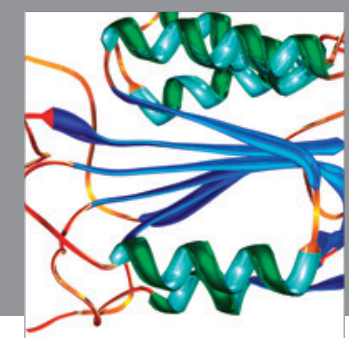

Disease Markers
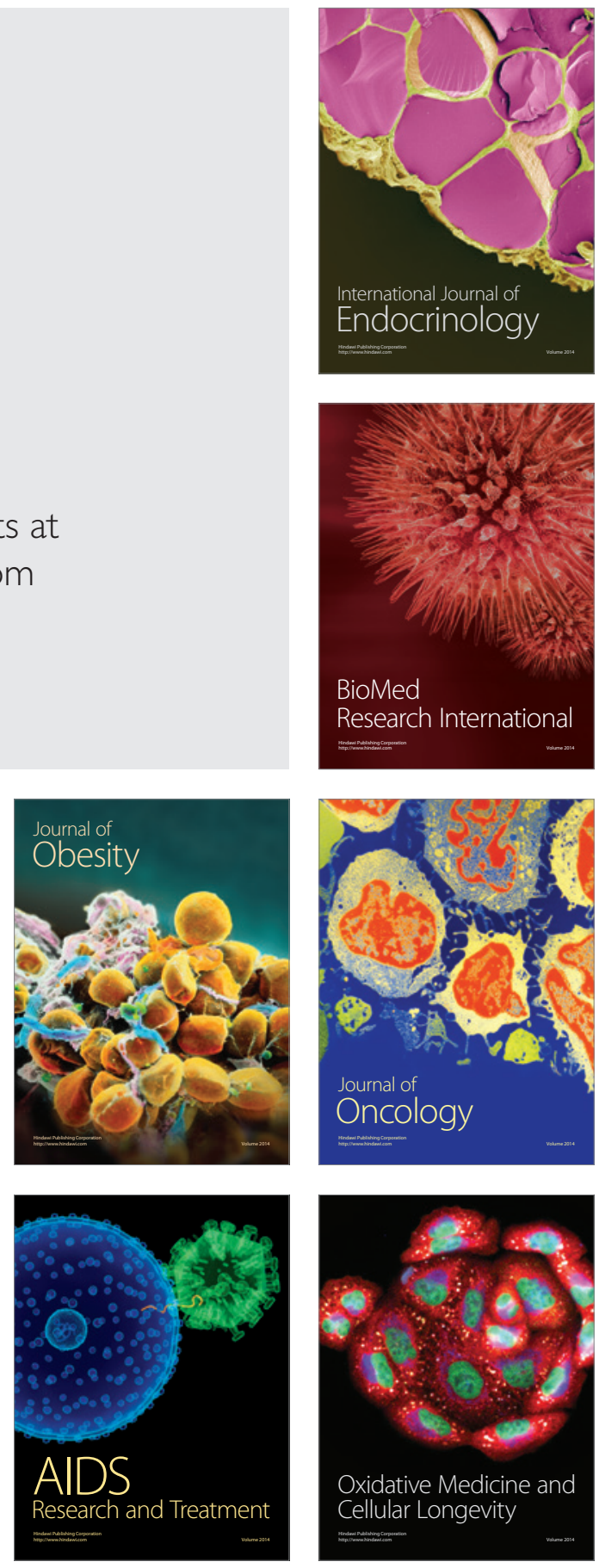